\title{
Gender- and age-related differences in osteoclast formation from circulating precursors
}

\author{
M Jevon, A Sabokbar, Y Fujikawa, T Hirayama, S D Neale, \\ J Wass and $\mathbf{N}$ A Athanasou \\ Department of Pathology, Nuffield Department of Orthopaedic Surgery, University of Oxford, Nuffield Orthopaedic Centre, Oxford OX3 7LD, UK \\ (Requests for offprints should be addressed to N A Athanasou; Email: nick.athanasou@ndos.ox.ac.uk)
}

\begin{abstract}
A number of bone diseases characterised by excessive osteolysis (e.g. osteoporosis and Paget's disease) exhibit a marked gender difference in prevalence and are more common in the elderly population. Bone resorption is carried out by osteoclasts, which are formed by fusion of circulating mononuclear precursor cells of haematopoietic origin. In this study, we have determined whether there are gender- and age-related differences in osteoclast formation from circulating precursors. Peripheral blood mononuclear cells (PBMCs) were co-cultured with UMR106 osteoblast-like cells in the presence of macrophage-colony stimulating factor (M-CSF) and 1,25 dihydroxyvitamin $\mathrm{D}_{3}\left(1,25(\mathrm{OH})_{2} \mathrm{D}_{3}\right)$ or cultured alone in the presence of sRANKL (soluble receptor activator of nuclear factor $\kappa \mathrm{B}$ ligand) and M-CSF. As assessed by the formation of tartrate resistant acid phosphatase (TRAP)positive $\left(\mathrm{TRAP}^{+}\right)$and vitronectin receptor-positive $\left(\mathrm{VNR}^{+}\right)$multinucleated cells (MNCs), there was no difference in the number of circulating osteoclast precursors in males and females. Lacunar resorption carried out by osteoclasts formed from these precursors was
\end{abstract}

generally increased in males compared with females $(P=0.03)$. An increase in the number of $\mathrm{TRAP}^{+}$and $\mathrm{VNR}^{+}$MNCs formed from male PBMCs was noted in response to $1,25(\mathrm{OH})_{2} \mathrm{D}_{3} \quad(P<0 \cdot 005)$. An increase in lacunar resorption in cultures of PBMCs $\left(10^{5}\right.$ per well) from males was also noted in response to $10^{-9} \mathrm{M}$ $1,25(\mathrm{OH})_{2} \mathrm{D}_{3}(P<0 \cdot 05)$ and sRANKL $(P=0 \cdot 05)$, but not $\mathrm{M}$-CSF. The addition of dexamethasone resulted in a marked increase in osteoclast formation and lacunar resorption in both males and females. Post-menopausal females and males of comparable age showed similar levels of osteoclastogenesis. Pre-menopausal women showed similar levels of osteoclastogenesis but less resorption $(P=0 \cdot 01)$ compared with males of comparable age. These results show that there are specific gender/age-related differences in osteoclast formation and bone resorption and have implications for evaluating osteoclastogenesis in skeletal diseases such as primary osteoporosis and Paget's disease.

Journal of Endocrinology (2002) 172, 673-681

\section{Introduction}

Bone is a dynamic tissue in which bone resorption by osteoclasts is tightly coupled to bone formation by osteoblasts. A number of bone diseases which are characterised by excessive osteolysis, such as osteoporosis and Paget's disease, exhibit discordant coupling of bone resorption and bone formation. These conditions are both more common in the elderly population and exhibit a marked gender difference in prevalence, primary involutional osteoporosis occurring more commonly in females and Paget's disease more commonly in males.

The osteoclast is a multinucleated cell (MNC) derived from the pluripotent haematopoietic stem cell (Suda et al. 1992). It has been shown that the human osteoclast precursor circulates in the monocyte fraction and exhibits a monocyte/macrophage phenotype (Fujikawa et al.
1996). Differentiation of these cells into osteoclasts requires the presence of macrophage-colony stimulating factor (M-CSF) and involves interaction between osteoclast precursors, which express the receptor activator of nuclear factor $\mathrm{\kappa B}$ (RANK), and osteoblastic cells, which express RANK ligand (RANKL) (Lacey et al. 1998, Nakagawa et al. 1998, Yasuda et al. 1998). This accords with the finding that human osteoclast formation from circulating mononuclear phagocyte precursors in vitro requires the presence of $\mathrm{M}-\mathrm{CSF}$ and either contact between osteoclast precursors and RANKL-expressing osteoblasts (Fujikawa et al. 1996) or the presence of soluble (s)RANKL (Matsuzaki et al. 1998, Quinn et al. 1998). 1,25 dihydroxyvitamin $\mathrm{D}_{3}\left(1,25(\mathrm{OH})_{2} \mathrm{D}_{3}\right)$ is also required for osteoclast formation when human monocytes are co-cultured with osteoblastic UMR106 cells (Fujikawa et al. 1996). $1,25(\mathrm{OH})_{2} \mathrm{D}_{3}$ has also been shown to 
stimulate osteoclast activity via osteoblasts (McSheehy \& Chambers 1987) and to promote osteoclast formation by increasing the ratio of RANKL to its soluble decoy receptor, osteoprotegerin (Tsukii et al. 1998, Nagai \& Sato 1999).

Differences in skeletal mass are known to be age- and sex-related (Looker et al. 1995). Increasing our understanding of the effects of age and gender on bone is important in the context of improved prevention and treatment of metabolic diseases of bone. A number of bone disorders which are characterised by a decrease in bone mass are known to occur more commonly in elderly individuals and to exhibit a marked gender difference. In this study we have focused on investigating whether there are gender- and age-related differences in osteoclast formation and activity.

\section{Materials and Methods}

\section{Materials}

All cell incubations were performed in alpha minimal essential medium (MEM) (Gibco, Paisley, Strathclyde, UK) supplemented with glutamine $(2 \mathrm{mM})$, benzyl penicillin $(100 \mathrm{IU} / \mathrm{ml})$, streptomycin $(100 \mu \mathrm{g} / \mathrm{ml})$ and $10 \%$ fetal calf serum (FCS) (Gibco) in a humidified atmosphere of $5 \% \mathrm{CO}_{2}$ at $37^{\circ} \mathrm{C}$. Cloned, hormone-responsive, calcitonin receptor-negative, osteoblast-like UMR106 cells (from a rat osteosarcoma-derived cell line) were obtained from Prof. T J Martin, Melbourne, Australia (Forest et al. 1985). 1,25(OH) ${ }_{2} \mathrm{D}_{3}$ (Solvay Duphar, Weesp, NL) and dexamethasone (Sigma Chemical Co., Poole, Dorset, UK) were dissolved in absolute alcohol and stored at $-20^{\circ} \mathrm{C}$. Human M-CSF (R\&D Systems Europe, Abingdon, Oxon, UK) and sRANKL (Amgen Inc., Thousand Oaks, CA, USA) were dissolved in MEM/FCS and stored at $-20{ }^{\circ} \mathrm{C}$.

\section{Preparation of monocyte-UMR106 co-cultures}

Monocytes were isolated from the peripheral blood of a total of 22 normal males (age range 25-86 years) and 22 normal females (age range 29-85 years). The menopausal status of the female subjects was ascertained at the time of blood collection by interview and all subjects classed as $<50$ years and $>50$ years were confirmed to be pre- and post-menopausal respectively. After collection, blood was diluted 1:1 in MEM, layered over Ficoll-Hypaque (Pharmacia, Milton Keynes, Bucks, UK), centrifuged at $693 \mathrm{~g}$ and washed and resuspended in MEM/FCS. The number of cells in the resulting suspension of peripheral blood mononuclear cells (PBMCs) was counted in a haemocytometer, after lysis of red cells with a $5 \%(\mathrm{v} / \mathrm{v})$ acetic acid solution.

Dentine slices (4 $\mathrm{mm}$ diameter), prepared as previously described (Boyde et al. 1984), and glass coverslips (6 mm diameter) were placed in 96-well tissue culture plates. UMR106 osteoblast-like cells $\left(2 \times 10^{4}\right)$ were added to each well and then cultured on the dentine slices and coverslips for $24 \mathrm{~h}$ in MEM/FCS. The cell suspension of PBMCs $\left(10^{5}\right.$ cells/well) was then settled on these coverslips and dentine slices for $2 \mathrm{~h}$. The coverslips and dentine slices were then removed from the wells, washed vigorously in MEM/FCS to remove non-adherent cells and cultured in 24-well tissue culture plates containing $1 \mathrm{ml} \mathrm{MEM} / \mathrm{FCS}$, with $1,25(\mathrm{OH})_{2} \mathrm{D}_{3}\left(10^{-7} \mathrm{M}\right)$, M-CSF $(25 \mathrm{ng} / \mathrm{ml})$ and dexamethasone $\left(10^{-8} \mathrm{M}\right)$ for up to 21 days. Media and added factors were entirely replaced every 3-4 days.

Preparation of monocyte cultures in the presence of $s R A N K L$

Monocytes were isolated from the peripheral blood of a total of 16 normal males (age range 25-83 years) and six normal females (age range $31-78$ years) as detailed above then seeded (alone) at $5 \times 10^{5}$ cells/well onto dentine slices/coverslips. After $2 \mathrm{~h}$ incubation, non-adherent cells were removed by washing in MEM/FCS and cell cultures on dentine slices and coverslips were placed in 24-well tissue culture plates containing $1 \mathrm{ml} \mathrm{MEM} / \mathrm{FCS}$, in the presence of sRANKL $(30 \mathrm{ng} / \mathrm{ml})$, M-CSF $(25 \mathrm{ng} / \mathrm{ml})$ and dexamethasone $\left(10^{-8} \mathrm{M}\right)$ and cultured for up to 21 days.

Assessment of the number of circulating osteoclast precursors in the monocyte fraction and relative sensitivity to osteoclastogenic factors

To compare the number of circulating osteoclast precursors present in male and female subjects, isolated PBMCs were serially diluted $\left(10^{2}-10^{5}\right.$ cells/well $)$ and co-cultured for 14-21 days with UMR106 cells on coverslips and dentine slices. Their relative sensitivity to $1,25(\mathrm{OH})_{2} \mathrm{D}_{3}$ $\left(10^{-10}-10^{-7} \mathrm{M}\right)$ was assessed in this PBMC-UMR106 co-culture system. The relative sensitivity of male and female circulating osteoclast precursors to sRANKL and M-CSF was assessed in the absence of UMR106 cells. PBMCs were seeded onto dentine slices and coverslips and cultured in the presence of sRANKL, M-CSF and dexamethasone as described above. The concentration of either sRANKL $(1-30 \mathrm{ng} / \mathrm{ml})$ or M-CSF $(5-25 \mathrm{ng} / \mathrm{ml})$ added to the PBMC cultures was altered.

\section{Histochemical and immunohistochemical characterisation of cultured cells}

Histochemical staining for tartrate resistant acid phosphatase (TRAP) was carried out using a commercially available kit (Sigma). Cell preparations were fixed in citrate/acetone solution and stained for acid phosphatase, using naphthol AS-BI phosphate as a substrate, in the presence of $1.0 \mathrm{M}$ tartrate; the product was reacted with Fast Garnet GBC salt (Minkin 1982). 


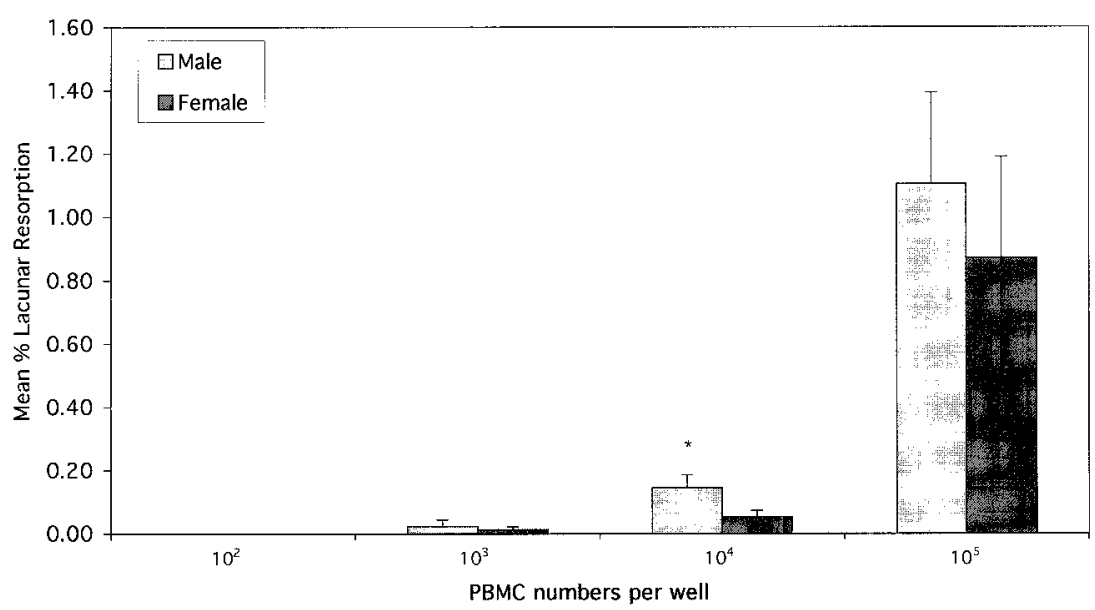

Figure 1 The effect of PBMC concentration on lacunar resorption in co-cultures of PBMCs from 20 age-matched male and female subjects incubated with UMR106 $\left(2 \times 10^{4}\right)$ cells in the presence of $1,25(\mathrm{OH})_{2} \mathrm{D}_{3}\left(10^{-7} \mathrm{M}\right), \mathrm{M}-\mathrm{CSF}(25 \mathrm{ng} / \mathrm{ml})$ and dexamethasone $\left(10^{-8} \mathrm{M}\right)$. The results are expressed as the mean percentage area resorbed per dentine slice \pm S.E.M. ${ }^{*} P<0 \cdot 05$, compared with females.

Cell preparations on coverslips were also stained immunohistochemically, by an indirect immunoperoxidase technique (Gatter et al. 1984), with the monoclonal antibody 23C6 (Serotec, Kidlington, Oxon, UK); this is directed against CD51, the vitronectin receptor (VNR), a highly osteoclast-associated antigen (Horton et al. 1985). Cell preparations were similarly stained with the monoclonal antibody GRS1, directed against CD14, a macrophage-associated antigen not known to be expressed by osteoclasts (Athanasou \& Quinn 1990). Coverslips were examined under light microscopy. The number of $\mathrm{TRAP}^{+}$and $\mathrm{VNR}^{+}$MNCs was counted in four fields of view ( $\times 10$ objective) per coverslip and the mean calculated. Cells containing three or more nuclei were considered multinucleated.

Functional evidence of osteoclast differentiation: detection of lacunar resorption

At the end of the co-culture period, dentine slices were placed in $\mathrm{NH}_{4} \mathrm{OH}(1 \mathrm{M})$ for $2 \mathrm{~h}$ and adherent cells removed by ultrasonication. The slices were then washed with distilled water and stained with $0.5 \%(\mathrm{v} / \mathrm{v})$ toluidine blue, then washed again. The surface was examined for evidence of lacunar resorption under light microscopy. This was quantified by calculating the percentage area of resorption on each slice, using image analysis software (Photoshop 5.5; Adobe, Adobe Systems UK, Oxbridge, Middlesex, UK).

\section{Statistical analysis}

Data are presented as means \pm S.E.M. Significant differences were determined using a two-tailed $t$-test. For the purposes of analysis, percentage data were normalised by arcsine transformation. $P<0 \cdot 05$ was taken as significant.

\section{Results}

Osteoclast formation and bone resorption in UMR106PBMC co-cultures: estimation of the relative proportion of circulating osteoclast precursors in males and females

Isolated PBMCs from both males and females cultured on coverslips showed the phenotypic profile of monocytes and not osteoclasts (Athanasou \& Quinn 1990). These cells expressed CD14 and were negative for the osteoclast markers TRAP and VNR after $24 \mathrm{~h}$ incubation. No evidence of lacunar resorption was noted following $24 \mathrm{~h}$ culture of PBMCs on dentine slices. Both male and female PBMCs co-cultured with UMR106 cells differentiated into osteoclasts as evidenced by the formation of numerous $\mathrm{TRAP}^{+}$and $\mathrm{VNR}^{+}$MNCs in 14 day co-cultures on coverslips and the production of lacunar resorption pits in 21 day co-cultures on dentine slices. In cultures of serial dilutions of PBMCs and UMR106 cells, incubated in

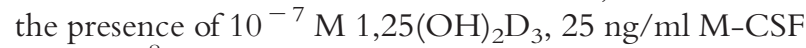
and $10^{-8} \mathrm{M}$ dexamethasone, osteoclast formation (as evidenced by TRAP and VNR expression and lacunar resorption) was first observed in both males and females when $10^{3}$ PBMCs were added to dentine slices and coverslips (Fig. 1).

Gender and age-related differences in osteoclast formation and bone resorption

No difference was noted in the number of $\mathrm{TRAP}^{+}$and $\mathrm{VNR}^{+}$MNCs formed in co-cultures of UMR106 cells 
Table 1 Mean \pm S.E.M. of $\mathrm{TRAP}^{+}$and $\mathrm{VNR}^{+}$MNCs (per high-power field) present in 14 day cultures on glass coverslips, in the

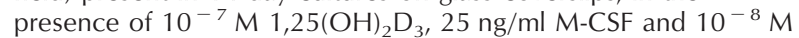
dexamethasone

$\begin{array}{llrr} & \text { TRAP }^{+} \mathbf{M N C s} & & \text { VNR }^{+} \text {MNCs } \\ \text { Male (29-86 years) } & 3 \cdot 90 \pm 0 \cdot 54 & & 10 \cdot 22 \pm 2 \cdot 96 \\ \text { Female (29-85 years) } & 3 \cdot 88 \pm 0 \cdot 50 & & 6 \cdot 32 \pm 1 \cdot 37 \\ \text { Male <50 years } & 5 \cdot 31 \pm 1 \cdot 21 & & 8 \cdot 67 \pm 2 \cdot 23 \\ \text { Female < 50 years } & 3 \cdot 88 \pm 0 \cdot 83 & & 5 \cdot 80 \pm 1 \cdot 48 \\ \text { Male > 50 years } & 3 \cdot 28 \pm 0 \cdot 54 & & 11 \cdot 00 \pm 4 \cdot 33 \\ \text { Female > 50 years } & 3 \cdot 88 \pm 0 \cdot 62 & & 6 \cdot 61 \pm 2 \cdot 86\end{array}$

with male and female PBMCs $\left(10^{5}\right.$ cells/well) (Table 1$)$. When the data were split in terms of age, i.e. $<50$ years and $>50$ years, there was also no significant difference in the number of $\mathrm{TRAP}^{+}$or $\mathrm{VNR}^{+} \mathrm{MNCs}$ formed in culture. When $10^{4}$ PBMCs were added to dentine slices, significantly more resorption was seen in males compared with females (Fig. 1, $P=0 \cdot 03$ ). This increase in resorption was not associated with a corresponding increase in the number of $\mathrm{TRAP}^{+}$or $\mathrm{VNR}^{+}$MNCs formed in culture. When $10^{5}$ PBMCs were added to dentine slices there was no overall difference in the extent of lacunar resorption in males and females. However, when the data were split in terms of age, a significant increase in lacunar resorption was noted in males $<50$ years compared with females $<50$ years. The extent of lacunar resorption was similar in males and females $>50$ years (Fig. 2). An increase in lacunar resorption in females $>50$ years compared with females $<50$ years was also noted but this did not reach statistical significance.
Sensitivity of circulating osteoclast precursors to osteoclastogenic factors in males and females

$\mathbf{1 , 2 5}(\mathrm{OH})_{2} \mathrm{D}_{3}$ When serial dilutions of $1,25(\mathrm{OH})_{2} \mathrm{D}_{3}$ were added to PBMC-UMR106 co-cultures, formation of $\mathrm{TRAP}^{+}$and $\mathrm{VNR}^{+} \mathrm{MNCs}$ and lacunar resorption was first noted in the presence of $10^{-9} \mathrm{M} 1,25(\mathrm{OH})_{2} \mathrm{D}_{3}$ in both males and females (Fig. 3). No osteoclast formation was noted in co-cultures to which $10^{-10} \mathrm{M} 1,25(\mathrm{OH})_{2} \mathrm{D}_{3}$ was added. An increase in the number of $\mathrm{TRAP}^{+}$and $\mathrm{VNR}^{+} \mathrm{MNCs}$ was noted in males when $10^{-9} \mathrm{M}$ and $10^{-8} \mathrm{M} \quad 1,25(\mathrm{OH})_{2} \mathrm{D}_{3}$ was added to co-cultures $(P<0.005$ and $P<0.05$ respectively). The mean number \pm S.E.M. of TRAP ${ }^{+}$and $\mathrm{VNR}^{+}$MNCs formed when $10^{-9} \mathrm{M}$ $1,25(\mathrm{OH})_{2} \mathrm{D}_{3}$ was added to co-cultures was $4 \cdot 20 \pm 1 \cdot 13$ and $9 \cdot 13 \pm 3.73$ respectively in males and $0.11 \pm 0.08$ and $1 \cdot 75 \pm 0.68$ respectively in females $(P<0 \cdot 005$ and $P<0 \cdot 05$ respectively as compared with male subjects). The mean number of $\mathrm{TRAP}^{+}$and $\mathrm{VNR}^{+} \mathrm{MNCs}$ formed when $10^{-8} \mathrm{M} 1,25(\mathrm{OH})_{2} \mathrm{D}_{3}$ was added to co-cultures was $7 \cdot 20 \pm 1.29$ and $8.08 \pm 3.31$ respectively in males and $3.00 \pm 0.57$ and $2.00 \pm 1.07$ respectively in females $(P<0 \cdot 05$ respectively as compared with male subjects). The mean number of TRAP ${ }^{+}$and $\mathrm{VNR}^{+} \mathrm{MNCs}$ formed when $10^{-7} \mathrm{M} 1,25(\mathrm{OH})_{2} \mathrm{D}_{3}$ was added to co-cultures was $6 \cdot 20 \pm 0.85$ and $7 \cdot 18 \pm 2.92$ respectively in males and $3 \cdot 24 \pm 1.67$ and $3.89 \pm 2 \cdot 17$ respectively in females. There was no significant difference in the mean number of $\mathrm{TRAP}^{+}$and $\mathrm{VNR}^{+}$MNCs formed in cultures containing PBMCs isolated from male or female subjects. Although all concentrations of $1,25(\mathrm{OH})_{2} \mathrm{D}_{3}$ resulted in an increase in the extent of lacunar resorption in male UMR106-PBMC co-cultures, compared with female subjects, the most significant difference was observed only when $10^{-9} \mathrm{M}$ $1,25(\mathrm{OH})_{2} \mathrm{D}_{3}$ was added to these co-cultures (Fig. 3).

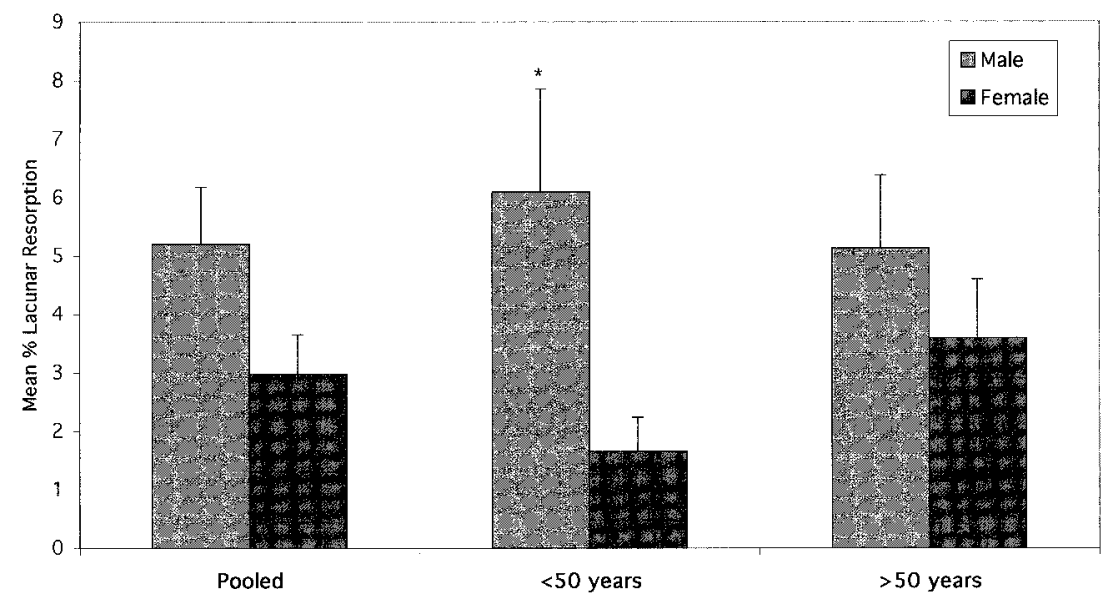

Figure 2 The effect of age on the extent of lacunar resorption in co-cultures of PBMCs $\left(10^{5}\right)$ from 22 age-matched male and female subjects incubated with UMR106 cells in the presence of $1,25(\mathrm{OH})_{2} \mathrm{D}_{3}\left(10^{-7} \mathrm{M}\right), \mathrm{M}-\mathrm{CSF}(25 \mathrm{ng} / \mathrm{ml})$ and dexamethasone $\left(10^{-8} \mathrm{M}\right)$. The results are expressed as the mean percentage area resorbed per dentine slice \pm S.E.M. ${ }^{*} P<0 \cdot 05$, compared with females. 


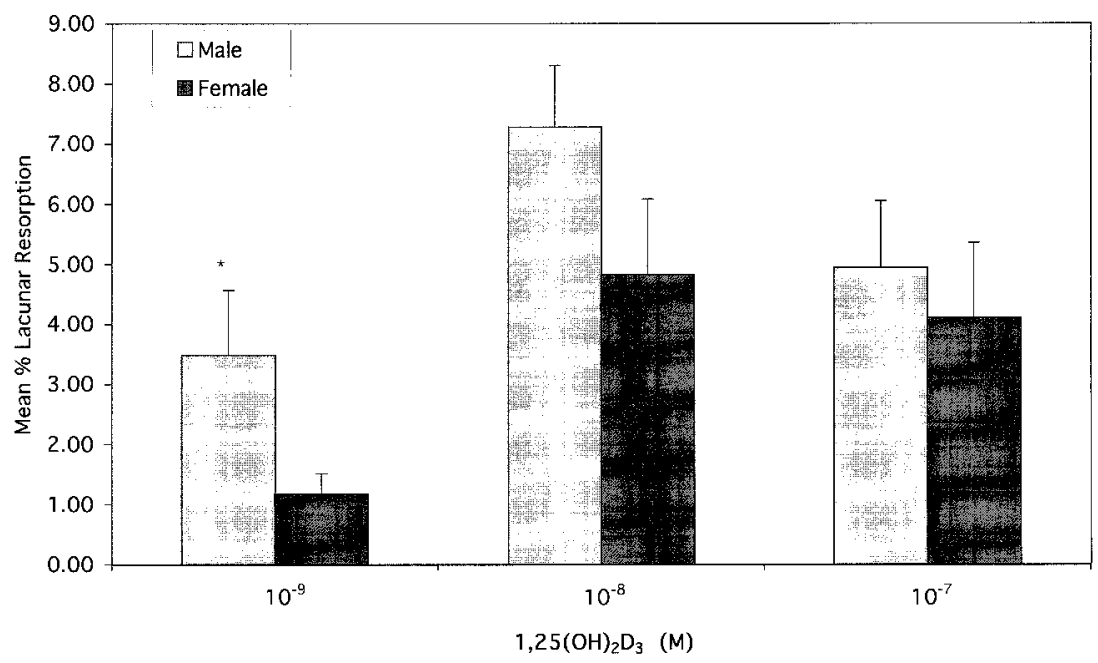

Figure 3 The effect of $1,25(\mathrm{OH})_{2} \mathrm{D}_{3}$ on lacunar resorption in co-cultures of PBMCs $\left(10^{5}\right)$ from 18 age-matched males and females incubated with UMR106 cells $\left(2 \times 10^{4}\right)$ in the presence of M-CSF $(25 \mathrm{ng} / \mathrm{ml})$ and dexamethasone $\left(10^{-8} \mathrm{M}\right)$. The results are expressed as the mean percentage area resorbed per dentine slice \pm S.E.M. ${ }^{*} P<0 \cdot 05$, compared with females.

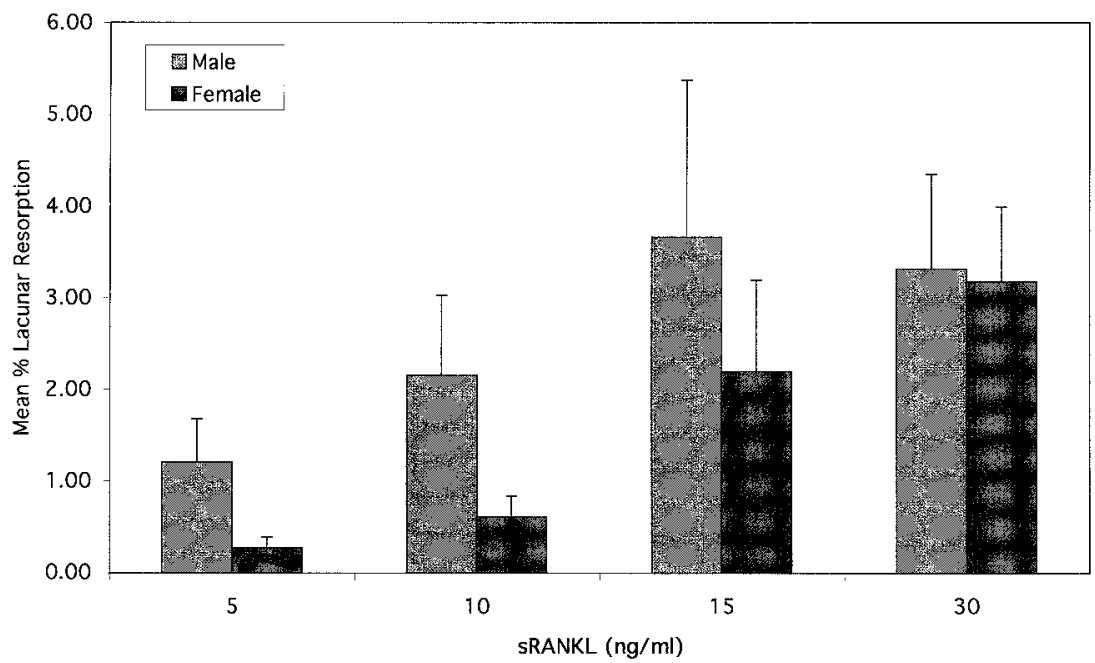

Figure 4 The effect of sRANKL on lacunar resorption in cultures of PBMCs $\left(10^{5}\right)$ from 12 males and 6 females (all age-matched) incubated in the presence of M-CSF $(25 \mathrm{ng} / \mathrm{ml})$ and dexamethasone $\left(10^{-8} \mathrm{M}\right)$. The results are expressed as the mean percentage area resorbed per dentine slice \pm S.E.M.

RANKL PBMCs incubated in the presence of sRANKL, $\mathrm{M}-\mathrm{CSF}$ and dexamethasone formed $\mathrm{TRAP}^{+}$and $\mathrm{VNR}^{+}$ MNCs in 14 day cultures on coverslips and lacunar resorption pits in 21 day cultures on dentine slices. When $30 \mathrm{ng} / \mathrm{ml}$ sRANKL was added to PBMC cultures, no difference in the extent of lacunar resorption between males and females was noted (Fig. 4). However, at lower concentrations of sRANKL, there was a trend for increased lacunar resorption in males compared with females. This reached statistical significance in PBMC cultures to which $5 \mathrm{ng} / \mathrm{ml}$ sRANKL was added (Fig. 4,
$P=0 \cdot 05)$. There was no evidence of osteoclast formation following the addition of $1 \mathrm{ng} / \mathrm{ml}$ sRANKL. No significant difference in the mean number of $\mathrm{TRAP}^{+}$and $\mathrm{VNR}^{+}$MNCs in male and female cultures was noted in response to the addition of varying concentrations of sRANKL. The mean number of $\mathrm{TRAP}^{+}$and $\mathrm{VNR}^{+}$ MNCs formed in PBMC cultures to which $30 \mathrm{ng} / \mathrm{ml}$ sRANKL was added is shown in Table 2.

M-CSF Sensitivity of osteoclast precursors from males and females to the osteoclastogenic effects of M-CSF was 
Table 2 Mean \pm S.E.M. of $\mathrm{TRAP}^{+}$and $\mathrm{VNR}^{+}$MNCs (per high-power field) present in 14 day cultures on glass coverslips, in the presence of $30 \mathrm{ng} / \mathrm{ml}$ sRANKL and $25 \mathrm{ng} / \mathrm{ml} \mathrm{M}$-CSF with or without $10^{-8} \mathrm{M}$ dexamethasone (Dex)

\begin{tabular}{|c|c|c|}
\hline & TRAP $^{+}$MNCs & $\mathrm{VNR}^{+} \mathrm{MNCs}$ \\
\hline $\begin{array}{l}\text { Male } \\
\text { +Dex } \\
\text { - Dex }\end{array}$ & $\begin{array}{l}1 \cdot 94 \pm 0.52^{a} \\
0 \cdot 71 \pm 0 \cdot 32\end{array}$ & $\begin{array}{l}6 \cdot 17 \pm 2 \cdot 53^{a} \\
0 \cdot 17 \pm 0 \cdot 11\end{array}$ \\
\hline $\begin{array}{l}\text { Female } \\
+ \text { Dex } \\
- \text { Dex }\end{array}$ & $\begin{array}{l}3 \cdot 01 \pm 0.57^{b} \\
0 \cdot 98 \pm 0 \cdot 18\end{array}$ & $\begin{array}{l}4 \cdot 75 \pm 1 \cdot 56^{b} \\
1 \cdot 25 \pm 0 \cdot 70\end{array}$ \\
\hline
\end{tabular}

assessed in cultures of PBMCs incubated in the absence of UMR106 cells but in the presence of sRANKL (30 ng/ $\mathrm{ml})$ and $\mathrm{M}-\mathrm{CSF}(5-25 \mathrm{ng} / \mathrm{ml})$. The number of TRAP ${ }^{+}$ and $\mathrm{VNR}^{+} \mathrm{MNCs}$ formed in culture was similar in males and females at all of the concentrations studied; the mean number of TRAP ${ }^{+}$and $\mathrm{VNR}^{+}$MNCs seen when $25 \mathrm{ng} /$ $\mathrm{ml} \mathrm{M-CSF}$ was added is shown in Table 2. No difference was noted in the extent of lacunar resorption in cultures of PBMCs from males or females at any of the concentrations studied (Fig. 5).

Corticosteroids Corticosteroids are known to influence bone remodelling with long-term use being associated with an increased risk of osteoporosis. The addition of dexamethasone to PBMC cultures, in the absence of UMR106 cells but in the presence of sRANKL and $\mathrm{M}-\mathrm{CSF}$, resulted in a significant increase in the formation of $\mathrm{TRAP}^{+}$and $\mathrm{VNR}^{+}$MNCs in both males and females (Table 2; $P<0.05$ and $P<0.05$ respectively). There was also an increase in the extent of lacunar resorption seen in cultures of both male and female PBMCs incubated in the presence of dexamethasone (Fig. 6; $P<0 \cdot 0001$ and $P<0 \cdot 01$ respectively). No significant difference in the extent of osteoclast formation (Table 2) or lacunar resorption (Fig. 6) was noted between male and female PBMCs cultured in the presence of dexamethasone.

\section{Discussion}

Differences in the formation and/or activity of osteoclasts in males and females could account for the marked gender difference in prevalence of some osteolytic bone disorders such as osteoporosis and Paget's disease. Mononuclear osteoclast precursors, which are known to circulate in the monocyte fraction of peripheral blood, form MNCs that express all the phenotypic characteristics of osteoclasts when cultured in contact with osteoblast-like UMR106 cells in the presence of M-CSF and $1,25(\mathrm{OH})_{2} \mathrm{D}_{3}$ (Fujikawa et al. 1996), or when cultured alone in the presence of M-CSF and sRANKL (Matsuzaki et al. 1998, Quinn et al. 1998).

By observing the extent of osteoclast formation in cultures of serial dilutions of these circulating precursors in age-matched males and females, we found no marked difference in the relative proportion of mononuclear osteoclast precursors in the peripheral blood of males and females. There was no difference in the number of $\mathrm{TRAP}^{+} / \mathrm{VNR}^{+}$MNCs formed from circulating precursors in age-matched males and females; these osteoclastassociated markers are expressed to a variable extent at different stages of osteoclast formation (Takahashi et al. 1994, Faust et al. 1999). The extent of lacunar resorption by osteoclasts formed in these PBMC cultures was similar in post-menopausal females and age-matched males but this was not the case for cultures of PBMCs from premenopausal females in which significantly less lacunar resorption was noted than in PBMC cultures from males of corresponding age. This observation accords with those of a recent study on age-related changes in bone turnover which found that there is an increase in markers of bone turnover, including bone resorption in young males (Fatayerji \& Eastell 1999). As we noted there was no significant increase in osteoclast formation in males less than 50 years, it would appear that this increase in resorption is due to increased functional activity or survival of osteoclasts formed from circulating precursors derived from males in this age group.

Although not directly comparable, it is interesting to consider our findings in the light of bone histomorphometry studies which have looked at the number of osteoclasts and the lacunar resorption surface area in males and females in different age groups. Most histomorphometry studies which have analysed the number of osteoclasts in bone have shown that this does not exhibit a marked gender difference and that osteoclast numbers in fact varies quite widely within a particular age group (Sedlin et al. 1963, Schenk et al. 1969, Meunier et al. 1973, Melsen et al. 1979, Rehman et al. 1994). Schenk et al. (1969) noted that the extent of Howship's lacunae covered by osteoclasts was similar in all age groups from $20-80$ years, indicating a remarkably constant state of osteoclast formation and activity. However, in other studies, no significant change with age or sex was noted in resorption area or resorption cavity depth, although these measurements are more likely to reflect osteoclast activity than osteoclast formation (Meunier et al. 1973, Croucher et al. 1991). Some studies have reported an increase in the extent of resorption in females in their sixth decade (Sedlin et al. 1963, Melsen et al. 1979), but this has been refuted by others (Meunier et al. 1973). Although our findings on osteoclast formation and bone resorption cannot strictly be equated to those of bone histomorphometry studies, it should be noted that post-menopausal females and age-matched males exhibited a similar level of lacunar resorption in our study. 


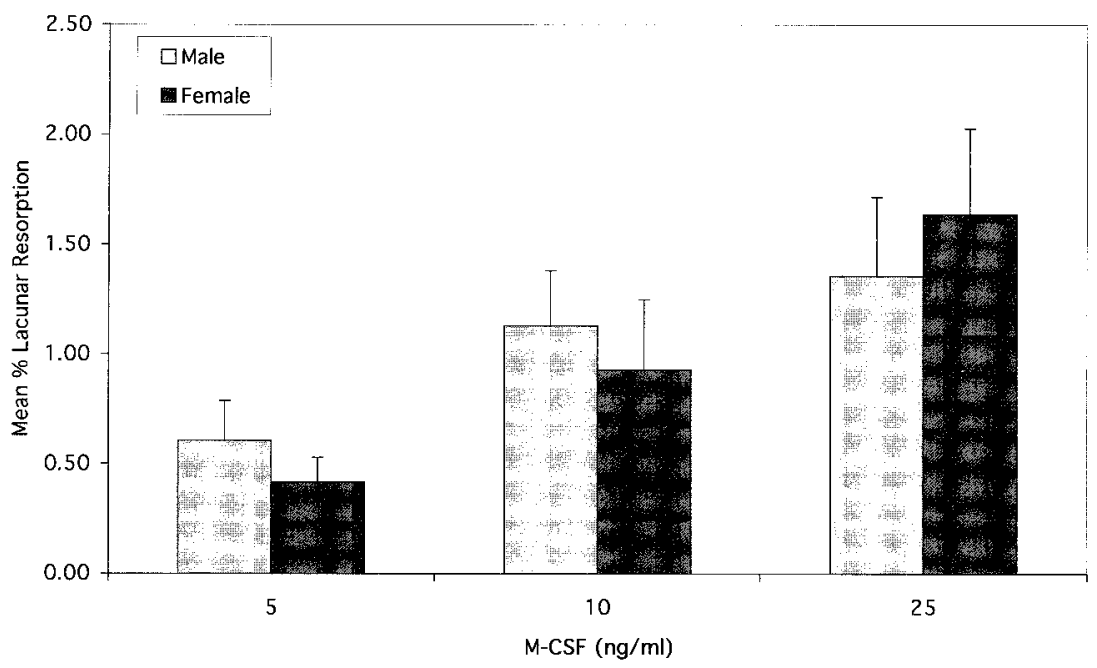

Figure 5 The effect of M-CSF on lacunar resorption in cultures of PBMCs from 16 males and 6 females (all age-matched) incubated in the absence of UMR106 cells but in the presence of sRANKL $(30 \mathrm{ng} / \mathrm{ml})$ and dexamethasone $\left(10^{-8} \mathrm{M}\right)$. The results are expressed as the mean percentage area resorbed per dentine slice \pm S.E.M.

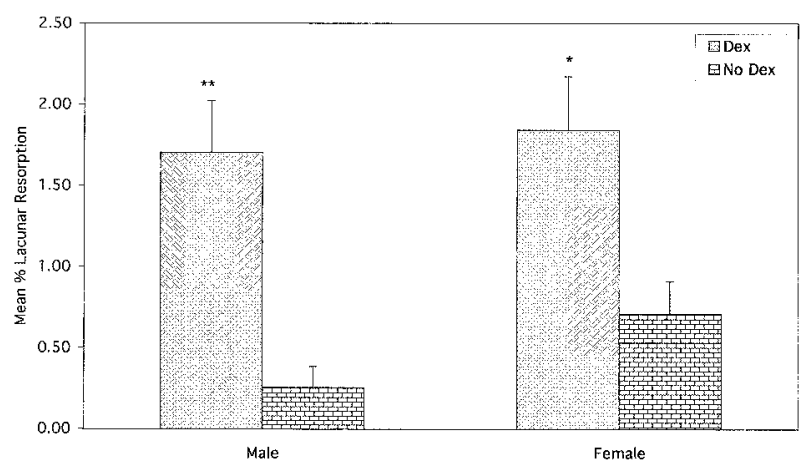

Figure 6 The effect of dexamethasone (Dex) on lacunar resorption in cultures of PBMCs from 16 males and 6 females (all agematched) incubated in the absence of UMR106 cells but in the presence of sRANKL $(30 \mathrm{ng} / \mathrm{ml})$ and M-CSF $(25 \mathrm{ng} / \mathrm{ml})$. The results are expressed as the mean percentage area resorbed per dentine slice \pm S.E.M. ${ }^{*} P<0 \cdot 05,{ }^{*} P<0 \cdot 001$, compared with females.

Of the osteoclastogenic factors examined, only $1,25(\mathrm{OH})_{2} \mathrm{D}_{3}$ was found to show a marked gender difference in osteoclast formation. The number of $\mathrm{TRAP}^{+}$and $\mathrm{VNR}^{+} \mathrm{MNCs}$ formed in co-cultures of UMR106 cells and PBMCs was increased in males compared with females; this increase in the number of $\mathrm{TRAP}^{+}$and $\mathrm{VNR}^{+} \mathrm{MNCs}$ in males was associated with a corresponding increase in lacunar resorption. This increased resorption in males could in part be due to $1,25(\mathrm{OH})_{2} \mathrm{D}_{3}$ stimulation of osteoclast formation; however, it should be noted that $1,25(\mathrm{OH})_{2} \mathrm{D}_{3}$ is also known to promote osteoclastic bone-resorbing activity via stimulation of osteoblastic cells (which were present in the co-cultures used in this study) (McSheehy \& Chambers 1987). Although no differences in serum levels of $25(\mathrm{OH})_{2} \mathrm{D}_{3}$ and $1,25(\mathrm{OH})_{2} \mathrm{D}_{3}$ have been noted in males and females (Haddad 1992), our finding of increased resorption in males is of interest with regard to the observation that PBMCs derived from patients suffering from Paget's disease, a condition which occurs predominantly in males, were also found to be hypersensitive to $1,25(\mathrm{OH})_{2} \mathrm{D}_{3}$ (Neale et al. 2000).

RANKL, a recently identified membrane-bound protein of the tumour necrosis factor (TNF) receptor family, promotes preosteoclast fusion and osteoclast survival and activity (Hofbauer et al. 2000). PBMCs from males and females were cultured in the presence of varying concentrations of sRANKL in order to assess their relative sensitivity. No difference in terms of the formation of $\mathrm{TRAP}^{+} / \mathrm{VNR}^{+} \mathrm{MNCs}$ was noted in cultures of PBMCs from males and females at any of the concentrations studied. However, a trend towards increased lacunar resorption by osteoclasts formed from male PBMCs at low concentrations of sRANKL was noted. This increased resorption may have been due to RANKL stimulation of osteoclast activity and survival rather than an effect on osteoclast formation (Burgess et al. 1999, Jimi et al. 1999). No significant difference was noted between males and females in response to varying concentrations of M-CSF, in terms of either TRAP and VNR expression or the extent of lacunar resorption. Although it has been shown that the membrane form of M-CSF is differentially regulated in rat bone marrow by oestrogens and androgens (Lea et al. 1999), our findings suggest that there is no M-CSFinduced difference in osteoclast formation in males and females. 
Corticosteroid treatment is a major risk factor for osteoporosis (Nishimura \& Ikuyama 2000). Dexamethasone is often used to promote osteoclastogenesis in vitro (Udagawa et al. 1990, Fujikawa et al. 1996, Itonaga et al. 1999). A significant reduction in bone resorption was seen when dexamethasone was excluded from cultures of both male and female PBMCs, although between the sexes no difference in the extent of osteoclast formation or lacunar resorption was noted following the addition of dexamethasone. Thus, it would appear that corticosteroids stimulate osteoclast formation and bone resorption and that this effect is not gender-related. Matsuzaki et al. (1998) showed that the increase in $\mathrm{TRAP}^{+}$cell numbers after dexamethasone administration was not significant but they did not study the effect of this treatment on the RANKL-induced lacunar resorption. Dexamethasone has been shown to increase osteoclast formation and lacunar resorption in human bone marrow cultures (Sarma et al. 1998). Dexamethasone is known to promote expression of membrane-bound M-CSF in murine osteoblasts but the mechanism whereby it stimulates osteoclast formation from circulating precursors is unknown (Rubin et al. 1998). Our own and previous studies suggest that this is due primarily to an effect on osteoclast proliferation and differentiation rather than osteoclast activity (Tobias \& Chambers 1989, Hirayama et al. 2000).

Specific gender and age differences in activity and hormonal response have been noted in osteoblastic boneforming cells obtained from human bone (Katzburg et al. 1999). The data presented in this study show that there are also differences in the formation and activity of boneresorbing cells in males and females. PBMCs from males were found to be more sensitive to $1,25(\mathrm{OH})_{2} \mathrm{D}_{3}$ than those of females, and osteoclasts formed in cultures from male PBMCs were more active in response to sRANKL. Our finding of a difference in the bone-resorbing activity of osteoclasts formed from PBMCs derived from premenopausal females and males of comparable age, and our observation that this difference is not evident in postmenopausal years, would also be in keeping with a role for female sex hormones in exerting an anti-resorptive effect in pre-menopausal years. Levels of oestrogen are significantly reduced in females following menopause, leading to changes in bone metabolism. Oestrogen is thought to exert its bone-protective effects by reducing production of cytokines and growth factors (e.g. interleukin-1 (IL-1), TNF- $\alpha$, IL-6 and M-CSF) which promote osteoclast formation and bone resorption (Manolagas \& Jilka 1995, Kimble et al. 1996, Pacifici 1996, Lin et al. 1997, Jilka 1998, Lea et al. 1999). Oestrogen also suppresses RANKL-induced osteoclast differentiation (Nakagawa et al. 1998, Shevde et al. 2000). Whether our findings reflect differences in the sensitivity of male and female osteoclast precursors or osteoclasts themselves to the effect of oestrogen and other humoral/hormonal factors requires further investigation. Certainly, these gender differences in osteoclast formation and activity should be taken into account when assessing studies of bone resorption in disorders that exhibit a marked gender difference in prevalence.

\section{Acknowledgements}

The authors wish to thank Caroline Costar for typing the manuscript. We are also grateful to all the volunteers who kindly donated blood samples for this study. We also extend our thanks to Dr D Lacey, Amgen Inc., for providing the sRANKL. This work was funded by the Wellcome Trust and the Nuffield Foundation.

\section{References}

Athanasou NA \& Quinn JM 1990 Immunophenotypic differences between osteoclasts and macrophage polykaryons: immunohistological distinction and implications for osteoclast ontogeny and function. Journal of Clinical Pathology 43 997-1004.

Boyde A, Ali NN \& Jones SJ 1984 Resorption of dentine by isolated osteoclasts in vitro. British Dental Journal 156 216-220.

Burgess TL, Qian Y, Kaufman S, Ring BD, Van G, Capparelli C, Kelley M, Hsu H, Boye WJ, Dunstan CR, Hu S \& Lacey DL 1999 The ligand for osteoprotegerin (OPGL) directly activates mature osteoclasts. Journal of Cell Biology 145 527-538.

Croucher PI, Garrahan NJ, Mellish RWE \& Compton JE 1991 Age-related change in resorption cavity characterisation in trabecular bone. Bone and Mineral 14 91-102.

Fatayerji D \& Eastell R 1999 Age-related changes in bone turnover in men. Journal of Bone and Mineral Research 14 1203-1210.

Faust J, Lacey DL, Hunt P, Burgess TL, Scully S, Van G, Eli A, Qian YX \& Shalhoub V 1999 Osteoclast markers accumulate. Journal of Cellular Biochemistry 72 67-80.

Forest SM, Ng KW, Findlay DM, Michelangeli VP, Livesy SA, Partridge NC, Zajac JD \& Martin TJ 1985 Characterization of an osteoblast-like clonal cell line which responds to both parathyroid and calcitonin. Calcified Tissue International 37 51-56.

Fujikawa Y, Quinn JMW, Sabokbar A, McGee JOD \& Athanasou NA 1996 The human osteoclast precursor circulates in the monocyte fraction. Endocrinology 137 4058-4060.

Gatter KC, Falini B \& Mason DY 1984 The use of monoclonal antibodies in histological diagnosis. In Recent Advances in Histopathology, no. 12, pp 35-36. Eds PP Anthony \& RNM MacSween. Edinburgh: Churchill Livingstone.

Haddad JG Jr 1992 Clinical aspects of measurements of plasma vitamin $\mathrm{D}$ steroids and the vitamin D binding protein. In Disorders of Bone and Mineral Metabolism, pp 195-216. Eds FL Coe \& MJ Favus. NY, USA: Raven Press.

Hirayama T, Athanasou NA \& Sabokbar A 2000 The effect of corticosteroids on human osteoclast formation and activity. Journal of Bone and Mineral Research 151233 (Abstract).

Hofbauer LC, Khosla D, Dunston CR, Lacey DL, Boyle WJ \& Riggs BL 2000 The roles of osteoprotegerin ligand in the paracrine regulation of bone resorption. Journal of Bone and Mineral Research 15 $2-12$.

Horton MA, Lewis D, McNulty K, Pringle JAS \& Chambers TJ 1985 Monoclonal antibodies for osteoclastomas (giant cell bone tumors): identification of osteoclast-specific antigens. Cancer Research $\mathbf{4 5}$ $5663-5669$

Itonaga I, Sabokbar A, Neale SD \& Athanasou NA 1999 1,25-Dihydroxyvitamin $\mathrm{D}_{3}$ and prostaglandin $\mathrm{E}_{2}$ act directly on circulating human osteoclast precursors. Biochemical and Biophysical Research Communications 264 590-595. 
Jilka RL 1998 Cytokines, bone remodelling, and oestrogen deficiency: a 1998 update. Bone 23 75-81.

Jimi E, Akiyama S, Tsurukai T, Okahashi N, Kobayashi K, Udagawa N, Nishira T, Takahashi N \& Suda T 1999 Osteoclast differentiation factor acts as a multifunctional regulator in murine osteoclast differentiation and function. Journal of Immunology 163 434-442.

Katzburg S, Lieberherr M, Orrnoy A, Klein BY, Hendel D \& Somjen D 1999 Isolation and hormonal responsiveness of primary human bone-derived cells: gender and age differences. Bone 25 667-673.

Kimble RB, Srivastava S, Ross FP, Matayoshi A \& Pacifici R 1996 Oestrogen deficiency increases the ability of stromal cells to support murine osteoclastogenesis via interleukin-1- and tumor necrosis factor-mediated stimulation of macrophage colony-stimulating factor production. Journal of Biological Chemistry 271 28890-28897.

Lacey DL, Timms E, Tan HL, Kelley MJ, Dunstan CR, Burgess T, Elliott R, Colombero A, Elliott G, Scully S, Hsu H, Sullivan J, Hawkins N, Davy E, Capparelli C, Eli A, Qian YX, Aufman S, Sarosi I, Shalhoub V, Senaldi G, Guo J, Delaney J \& Boyle WJ 1998 Osteoprotegerin ligand is a cytokine that regulates osteoclast differentiation and activation. Cell 93 165-176.

Lea CK, Sarma U \& Flanagan AM 1999 Macrophage colony stimulating-factor transcripts are differentially related in rat bone-marrow by gender hormones. Endocrinology 140 273-279.

Lin SC, Yamate T, Taguchi Y, Borba V, Girasole G, O’Brien CA, Belbeido T, Abe E \& Manolagas SC 1997 Regulation of the gp80 and gp130 subunits of the IL-6 receptors by sex steroids in the murine bone marrow. Journal of Clinical Investigation $\mathbf{1 0 0}$ 1980-1990.

Looker AC, Wahner HW, Dunn WL, Calvo MS, Harris TB, Heyse SP, Johnston CC \& Lindsay RL 1995 Proximal femur bone and mineral levels of US adults. Osteoporosis International 5 389-409.

Manolagas SC \& Jilka RL 1995 Bone marrow, cytokines, and bone remodeling: emerging insights into the pathophysiology of osteoporosis. New England Journal of Medicine 332 305-311.

Matsuzaki K, Udagawa N, Takahashi N, Yamaguchi K, Yasuda H, Shima N, Morinaga T, Toyama Y, Yabe Y, Higashio K \& Suda T 1998 Osteoclast differentiation factor (ODF) induces osteoclast-like cell formation in human peripheral blood mononuclear cell cultures. Biochemical and Biophysical Research Communications 246 199-204.

McSheehy PMJ \& Chambers TJ 1987 1,25 dihydroxy vitamin $D_{3}$ stimulates rat osteoblastic cells to release a soluble factor that increase osteoclastic bone resorption. Journal of Clinical Investigation $80425-429$.

Melsen F, Melsen B, Mosekilde L \& Bergmann S 1979 Histomorphometric analysis of normal bone from the iliac crest. Acta Pathologica et Microbiologica Scandinavica 91 545-561.

Meunier P, Courpron P, Edouard C, Bernard J, Bringuier J \& Vignon G 1973 Physiological senile involution and pathological rarefaction of bone. Quantitative and comparative histological data. Clinical Endocrinology and Metabolism 2 239-256.

Minkin C 1982 Bone acid phosphatase: tartrate-resistant acid phosphatase as a marker of osteoclast function. Calcified Tissue International 34 285-290.

Nagai M \& Sato N 1999 Reciprocal gene expression of osteoclastogenesis inhibitory factor and osteoclast differentiation factor regulates osteoclast formation. Biochemical and Biophysical Research Communications 257 719-723.

Nakagawa N, Kinosaki M, Yamaguchi K, Shima N, Yasuda H, Yano K, Morinaga T \& Higashio K 1998 RANK is the essential signaling receptor for osteoclast differentiation factor in osteoclastogenesis. Biochemical and Biophysical Research Communications 253 395-400.
Neale SD, Smith R, Wass JA \& Athanasou NA 2000 Osteoclast differentiation from circulating mononuclear precursors in Paget's disease is hypersensitive to 1,25-dihydroxyvitamin $\mathrm{D}_{3}$ and RANKL. Bone 27 409-416.

Nishimura J \& Ikuyama S 2000 Glucocorticoid-induced osteoporosis: pathogenesis and management. Journal of Bone and Mineral Metabolism 18 350-352.

Pacifici R 1996 Estrogen, cytokines, and pathogenesis of postmenopausal osteoporosis. Journal of Bone and Mineral Research 11 1043-1051.

Quinn JMW, Elliott J, Gillespie MT \& Martin TJ 1998 A combination of osteoclast differentiation factor and macrophage-colony stimulating factor is sufficient for both human and mouse osteoclast formation. Endocrinology 139 4424-4427.

Rehman MT, Hoyland JA, Denton J \& Freemont AJ 1994 Age-related histomorphometric changes in bone in normal British men and women. Journal of Clinical Pathology 47 529-534.

Rubin J, Biskobong DM, Jadhav L, Fan D, Nanes MS, Perkins S \& Fan X 1998 Dexamethasone promotes expression of membranebound macrophage colony-stimulating factor in murine osteoblast-like cells. Endocrinology 139 1006-1012.

Sarma U, Edwards M, Motoyoshi K \& Flanagan AM 1998 Inhibition of bone resorption by $17 \beta$-estradiol in human bone marrow cultures. Journal of Cellular Physiology 175 99-108.

Schenk RK, Merz NA \& Muller J 1969 A quantitative histological study on bone resorption in human cancellous bone. Acta Anatomica 74 44-53.

Sedlin ED, Villaneuva AR \& Frost HM 1963 Age variations in the specific surface of Howship's lacunae as an index of human bone resorption. Anatomical Record 146 201-207.

Shevde NK, Bendixen AC, Dienger KM \& Pike W 2000 Estrogens suppress RANK ligand-induced osteoclast differentiation via a stromal cell independent mechanism involving c-Jun repression. PNAS 97 7829-7834.

Suda T, Takahashi N \& Martin TJ 1992 Modulation of osteoclast differentiation. Endocrine Reviews 13 66-68.

Takahashi N, Udagawa N, Tanaka S, Murakami H, Owan I, Tamura T \& Suda T 1994 Postmitotic osteoclast precursors are mononuclear cells which express macrophage-associated phenotypes. Developmental Biology 163 212-221.

Tobias J \& Chambers TJ 1989 Glucocorticoids impair bone resorptive activity and viability of osteoclasts disaggregated from neonatal rat long bones. Endocrinology 125 1290-1295.

Tsukii K, Shima N, Mochizuki S-I, Yamaguchi K, Kinosaki M, Yano K, Shibata O, Udagawa N, Yasuda H, Suda T \& Higashio K 1998 Osteoclast differentiation factor mediates an essential signal for bone resorption induced by $1 \alpha 25$-dihydroxyvitamin $\mathrm{D}_{3}$, prostaglandin $\mathrm{E}_{2}$, or parathyroid hormone in the microenvironment of bone. Biochemical and Biophysical Research Communications 246 337-341.

Udagawa N, Takahashi N, Akatsu T, Tanaka H, Sasaki T, Nishihara T, Martin TJ \& Suda T 1990 Origin of osteoclasts: mature monocytes and macrophages are capable of differentiating into osteoclasts under a suitable microenvironment prepared by bone marrow-derived stromal cells. PNAS 87 7260-7264.

Yasuda H, Shima N, Nakagawa N, Yamaguchi K, Kinosaki M, Mochizuki S-I, Tomoyasu A, Yano K, Goto M, Murakami A, Tsuda E, Morinaga T, Higashio K, Udagawa N, Takahashi N \& Suda T 1998 Osteoclast differentiation factor is a ligand for osteoprotegerin/osteoclastogenesis-inhibitory factor and is identical to TRANCE/RANKL. PNAS 95 3597-3602.

Received 27 September 2001 Accepted 26 October 2001 